\title{
Correlations of Student Grades and Behavior While Using a Course Management System Under Different Contexts
}

\author{
George M. Nickles III \\ Information Technology and Science (ITS) Center for Teaching and \\ Learning, Texas A\&M University
}

\begin{abstract}
As the Internet is in widespread use by engineering faculty, the opportunity exists to collect measures of student learning behavior based on their use of the Internet learning tools. One such tool is a course management system (CMS). Data on student use of a CMS is readily available from login records and the web server log file. It has been shown that this data, paired with contextual information about the CMS, such as which files are related to course content or to assignments, can be used to generate measures of student behavior that significantly correlate with the students' final grades in the course. These measures can add a typically unobtainable set of information about student behavior outside the classroom to the instructor's overall efforts in evaluating a course.

However, measures of student interaction with a CMS must be examined in context of how that CMS is used with the class. Patterns of student interaction may be very different if the CMS is used as a database of information or as an interactive learning tool. A previous study of two courses delivered by a CMS where one was used as a database of information and the other as an interactive learning tool in addition to a database showed that measures had different results and had different correlation patterns with student grades.

To further examine patterns of student interaction with a CMS in relation to grades, data were collected for individual students on six measures of student behavior over the entire semester from seven courses delivered by a CMS. These measures are total time logged in to the CMS, average length of visits, total number of logins, total hits on any course content file, total hits on the main course page, and total hits on the course assignments page. The seven courses are categorized according to how the CMS is used in supporting their courses and what functions were employed. For each course, the six measures were paired with final grades for each student and examined in a correlation analysis. The patterns of correlations between courses are discussed in the paper along with implications for making general guidelines for interpreting measures of student behavior as measured through a CMS.
\end{abstract}

\section{Introduction}

In a survey of engineering educators in $2001,79 \%$ indicated the use of some aspect of the Internet in teaching their courses. ${ }^{5}$ One way to use the Internet in education is administration of 
a course using a course-management system (CMS). The previously mentioned survey also indicated that $67 \%$ of engineering educators who use the Internet in their courses report using a CMS (assuming responders did not use more than one brand of CMS). As Internet-based CMSs are in fairly widespread use, there is an urgent need to include interaction with them in evaluating expected learning outcomes of the course.

One source of evaluation data for a CMS is web server logs. Web server software can be configured to keep a log of user interactions with the website, typically recording every file that is requested from the server, when requested, and the IP address of the device that requested it. Like other electronic measures of student behavior, web server logs are fully objective and record every interaction with the server. Also, electronic logs can capture student behavior outside the classroom, which is not typically feasible to collect. As Ingram ${ }^{1}$ states, if we want to use server logs for evaluation "[w]e would do that by gathering performance assessments for the students and correlating them with actual Web use" (p. 153).

While electronic logs can be useful, they must be considered in the context in which they are collected. As is known from ecological design, the structure of a system's environment significantly shapes and constrains behavior. ${ }^{2}$ For example, students can be expected to exhibit different behavior in a course with weekly homework assignments and four exams as compared to a course where the only graded assignment is a design project. The same is true for a course website, where student behavior is constrained by the functions and content available. Even among courses using the same CMS, different instructors may have different pedagogical approaches and choose to use different functions of the CMS. Thus, it is important to consider how a CMS is used when interpreting measures made of its use.

One example of this can be seen in a recent study that compared the pattern of student interaction with a CMS and grades for two courses. ${ }^{3}$ In this study, six student behavior measures taken from their interaction with a CMS were collected from the same course taught by the same instructor in different semesters. The main difference between the courses was the use of more interactive components in the CMS in the second semester. Of the six measures, three were negatively correlated with final grades in the first semester and the other three were positively correlated with grades in the second semester. This difference in correlation patterns implies that the context in which the measures were collected (the different functions used in the CMS) made a significant difference in what the measures indicated about student learning.

To examine other contexts for these measures of student behavior, these six measures have been collected for five other courses that use the same CMS in different contexts. In all seven courses, the measures are collected for each student, paired with the student's final grade, and used in a correlation analysis. The method for collecting this data, the analysis, and conclusions are presented below.

\section{Method}

Students' final grades and measures of behavior based on web server log activity were collected for students in seven courses that used ITWeb, ${ }^{4}$ a CMS developed in the School of Industrial and Systems Engineering at Georgia Tech. A correlation analysis was performed for data in each course examining grades and six measures of student behavior. 


\section{Course and Subjects}

Data for this study comes from seven courses, all taught in the same department, which are described in Table 1. Courses A-C are the same course taught by the same instructor in different semesters. Courses D-F are different courses taught by the same instructor. Course $\mathrm{G}$ is the same course as E though taught by a third instructor in a different term. Table 1 also shows how many students of the total in each course consented to allow their data to be used for research purposes. Courses A and B are the courses examined in the previous study. ${ }^{3}$

Table 1: Description of courses examined

\begin{tabular}{|c|c|c|c|c|}
\hline $\begin{array}{c}\text { Course } \\
\text { Code }\end{array}$ & Description & Instructor & Term & $\begin{array}{c}\text { Consenting/Total } \\
\text { Students }\end{array}$ \\
\hline A & $\begin{array}{c}\text { Senior level human- } \\
\text { integrated design }\end{array}$ & I & Spring, 2002 & $35 / 80$ \\
\hline B & $\begin{array}{c}\text { Senior level human- } \\
\text { integrated design }\end{array}$ & I & Spring, 2003 & $49 / 53$ \\
\hline C & $\begin{array}{c}\text { Senior level human- } \\
\text { integrated design }\end{array}$ & I & Spring, 2004 & $97 / 112$ \\
\hline D & Graduate level statistics & II & Spring, 2004 & $15 / 22$ \\
\hline E & Sophomore level statistics & II & Summer, 2003 & $32 / 40$ \\
\hline F & Graduate level probability & II & Summer, 2003 & $17 / 29$ \\
\hline G & Sophomore level statistics & III & Spring, 2004 & $33 / 48$ \\
\hline
\end{tabular}

These courses can be distinguished by the amount of learning content that was posted for students and by different use of CMS functions. Table 2 shows that courses B and C use the interactive tools provided to teachers and students in addition to the course materials delivery system in their own classes. The other courses use ITWeb as a database of information for students. Also, the courses differ in the number of course content files the instructor posted.

Table 2: Utilization of ITWeb by each course

\begin{tabular}{|c|c|c|c|c|}
\hline $\begin{array}{c}\text { Course } \\
\text { Code }\end{array}$ & $\begin{array}{c}\text { Number of Course } \\
\text { Content Files }\end{array}$ & $\begin{array}{c}\text { Use } \\
\text { Discussion } \\
\text { Board }\end{array}$ & $\begin{array}{c}\text { Use Peer } \\
\text { Review } \\
\text { Component }\end{array}$ & $\begin{array}{c}\text { Use User Group } \\
\text { Component }\end{array}$ \\
\hline A & 64 & No & No & No \\
\hline B & 85 & Yes & Yes & Yes \\
\hline C & 80 & No & Yes & Yes \\
\hline D & 49 & No & No & No \\
\hline E & 13 & No & No & No \\
\hline F & 12 & No & No & No \\
\hline G & 10 & No & No & No \\
\hline
\end{tabular}




\section{Student Behavior Measures}

Six measures of student behavior were collected from the server log and ITWeb login data (Table 3). These are the same measures as were collected over an entire course in the previous study. ${ }^{3}$

\section{Table 3: Measures of Student Behavior Collected Over an Entire Course}

\begin{tabular}{|l|l|}
\hline \multicolumn{1}{|c|}{ Measurement } & \multicolumn{1}{c|}{ Explanation } \\
\hline $\begin{array}{l}\text { Total time logged in to } \\
\text { ITWeb }\end{array}$ & $\begin{array}{l}\text { Total amount of time in seconds between each login and logout time } \\
\text { when the visit includes at least one hit on the main course page }\end{array}$ \\
\hline $\begin{array}{l}\text { Average length of } \\
\text { visits }\end{array}$ & $\begin{array}{l}\text { Average time in seconds between each login and logout that include } \\
\text { at least one hit on the main course page }\end{array}$ \\
\hline Total number of visits & $\begin{array}{l}\text { Total number of logins made that include at least one hit on the main } \\
\text { course page }\end{array}$ \\
\hline $\begin{array}{l}\text { Total hits on course } \\
\text { content files }\end{array}$ & $\begin{array}{l}\text { Total number of hits on any file on the website containing course } \\
\text { content }\end{array}$ \\
\hline $\begin{array}{l}\text { Total hits on the main } \\
\text { course page }\end{array}$ & Total number of hits on the main course web page \\
\hline $\begin{array}{l}\text { Total hits on the } \\
\text { course assignment } \\
\text { page }\end{array}$ & $\begin{array}{l}\text { Total number of hits on the course assignment page, the only way to } \\
\text { access assignments }\end{array}$ \\
\hline
\end{tabular}

\section{Data Collection}

ITWeb is designed in part to be able to track individual student behavior using a login system and the server log. To access course content, students must login to ITWeb. ITWeb is based on a MySQL database and the PHP programming language, using the "sessions" feature of PHP to control login and logout of users. When students login, a record is inserted into a table of the database recording the time, IP address, and the user. If students click the logout button (visible on nearly every page), the time they logout is recorded in this record. If students do not logout but simply close the browser, a perl script analyzes the other logins and entries in the log file to determine approximately what time the student stopped using the website. With this system, all hits in one visit by one student can be identified with that student. Also, knowledge of the site's contents can reveal what the student requested and possibly viewed during each visit.

A perl script extracts the data from the server log files. The script matches server log data from the consenting students with their logins to collect measurements of their behavior. Students' final grades in the courses are stored in the database and were retrieved for analysis.

\section{Analysis Plan}

Following the pattern of previous studies, trends in processes measures collected across the entire course will be compared to students' final grade. Due to the exploratory nature of this study, an alpha level of 0.10 will be used to determine whether or not a correlation is significant. 


\section{Results and Discussion}

Boxplots of the data for each measure can be seen in Figures 1-6. It should be noted that the large difference seen in Figure 5 between courses A and B and the rest is likely due to a change in the design of ITWeb made between spring and summer of 2003. This change involved moving more components of ITWeb to separate pages rather than having them all on the main course page. Thus, the main course page transitioned to being an entry point for the course. Also, data in Figure 4 has been transformed to the average number of hits on content files per file so that the data can be compared across courses with different numbers of content files.

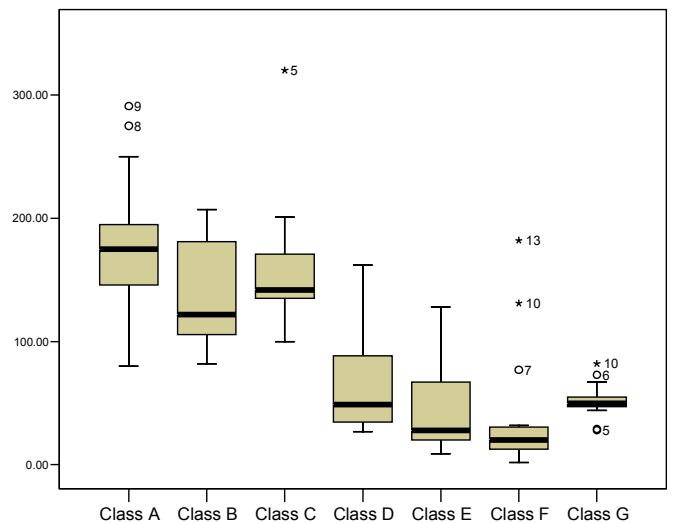

Figure 1: Total Number of Visits

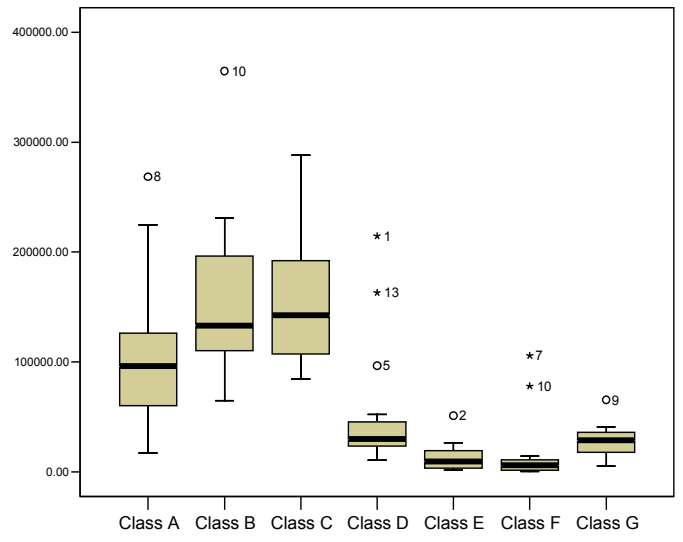

Figure 2: Total Time Logged In (seconds)

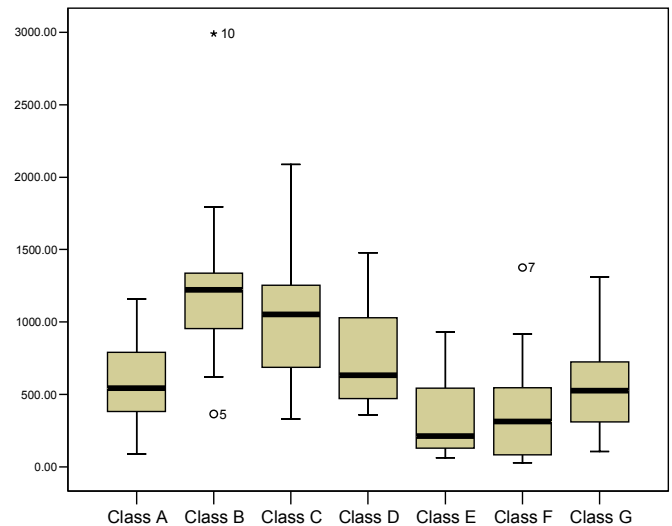

Figure 3: Average Time Per Visit (seconds)

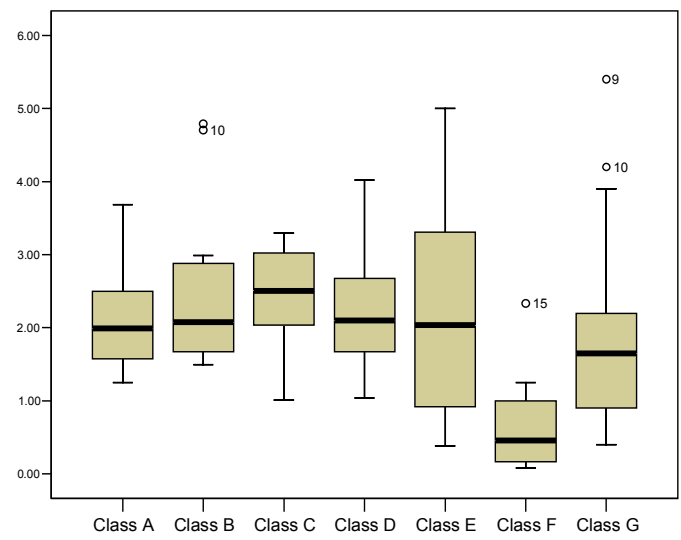

Figure 4: Average Content File Hits 


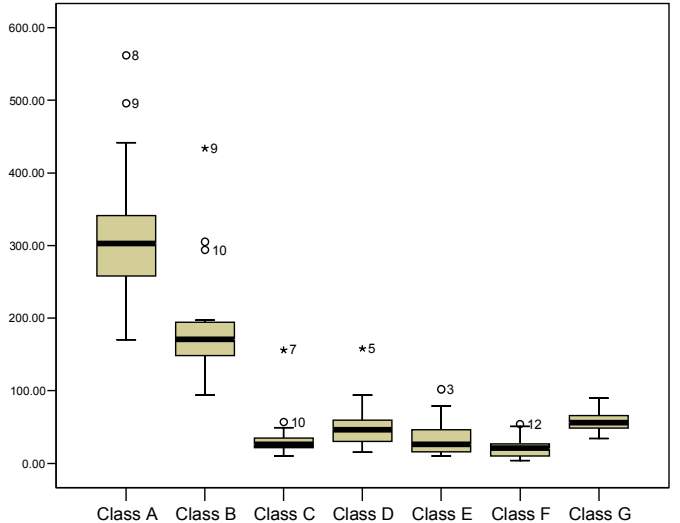

Figure 5: Total Course Page Hits

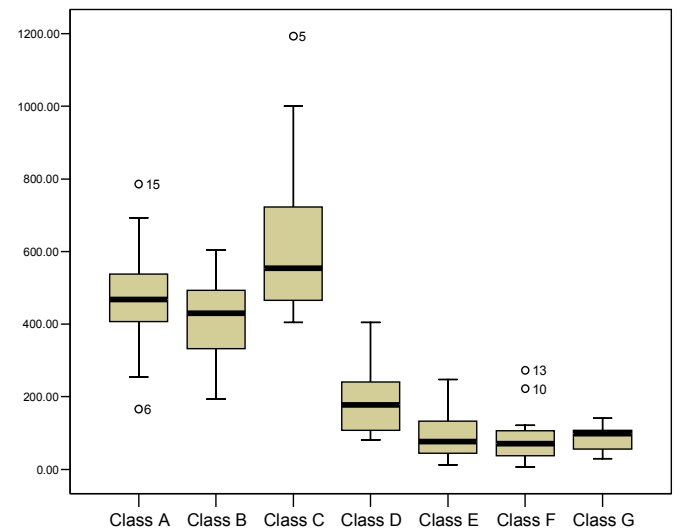

Figure 6: Total Assignment Page Hits

Table 4 presents the significant correlations between the six measures collected and the final grades in the course. There are several measures of student behavior that correlate with grades, but the pattern of these is generally inconsistent. Within instructors, correlation patterns for instructor I are only consistent for two measures between courses B and C. Instructor II consistently had no behavior measures correlate with grades. Courses E and G, though the same course (taught by different instructors in different semesters) did not have totally consistent correlation patterns. Also, all courses that did not use more interactive components of ITWeb (all courses except B and C) do not have a consistent pattern of correlations.

One pattern that can be seen is that two measures are consistently correlated with grades in courses B and C. These are also the only two courses that use the interactive tools of peer review and user groups. While not conclusive, this may indicate a pattern that could be examined further.

Table 4: Significant Correlations Between Final Grades and Behavior Measures (p-values)

\begin{tabular}{|c|c|c|c|c|c|c|c|}
\hline Course & $\mathbf{N}$ & $\begin{array}{c}\text { Total } \\
\text { Visits }\end{array}$ & $\begin{array}{c}\text { Average } \\
\text { Visit Time }\end{array}$ & $\begin{array}{c}\text { Total Login } \\
\text { Time }\end{array}$ & $\begin{array}{c}\text { Total } \\
\text { Topic } \\
\text { Hits }\end{array}$ & $\begin{array}{c}\text { Total } \\
\text { Course } \\
\text { Page Hits }\end{array}$ & $\begin{array}{c}\text { Total } \\
\text { Assignment } \\
\text { Page Hits }\end{array}$ \\
\hline A & 35 & & $\begin{array}{c}-0.522 \\
(0.001)\end{array}$ & $\begin{array}{c}-0.325 \\
(0.057)\end{array}$ & $\begin{array}{c}-0.297 \\
(0.084)\end{array}$ & & \\
\hline B & 49 & $\begin{array}{c}0.308 \\
(0.031)\end{array}$ & & & & 0.342 & $(0.016)$ \\
\hline C & 96 & $\begin{array}{c}.278 \\
(0.006)\end{array}$ & & & & & $\begin{array}{c}.242 \\
(0.093)\end{array}$ \\
\hline D & 15 & & & & & & .232 \\
E & 32 & & & & & & \\
\hline F & 17 & & & & & & \\
\hline G & 33 & & & & -0.328 & & \\
\hline
\end{tabular}




\section{Conclusion}

In the courses studied here, the six measures of student behavior did not consistently correlate with grades across all courses. Nor was there a consistent pattern of correlation for courses with different instructors or for courses where ITWeb was used as a content database. While this study includes only a small sample of courses and specific results may not be generalizable to all courses, the study does show that it is difficult to identify generally applicable measures of student behavior based on web server logs that are related to performance measures.

It is conjectured that attempting to devise such generally applicable measures of student behavior based on web server logs may be very difficult if not impossible due to the wide difference in contexts in which those measures will be collected, and thus the wide variety of learning behavior that students may exhibit. If true, identifying measures of student behavior that correlate with performance measures will involve more focused measurement methods devised for the individual tool and context.

\section{Acknowledgements}

The author would like to thank Dr. Amy Pritchett of Georgia Tech for her support in this work. This paper is based on work supported by the National Science Foundation under Grant No. 0083336.

\section{References}

1. A. L. Ingram, "Using Web Server Logs in Evaluating Instructional Web Sites," Journal of Educational Technology Systems, vol. 28, pp. 137-157, 1999-2000.

2. A. Kirlik, "Requirements for Psychological Models to Support Design: toward Ecological Task Analysis," in Global Perspectives on the Ecology of Human-Machine Systems, J. Flach, P. Hancock, J. Caird, and K. J. Vicente, Eds. Hillsdale, NJ: Lawrence Erlbaum Associates, 1995, pp. 68-120.

3. G. M. Nickles, "Identifying measures of student behavior from interaction with a course management system," Journal of Educational Technology Systems, submitted.

4. A. Pritchett, A. Quinn, G. Nickles, M. Ashok, M. Iken, and J. C. Lu, "Internet Based Curriculum Innovation in Information Engineering and E-Business: The Integrated Curriculum Delivery System.," in the Proceedings of the American Society for Engineering Education Annual Conference, Montréal, Canada, 2002.

5. S. St. Clair and N. C. Baker, "Faculty use and impressions of courseware management tools: A national survey," Journal of Engineering Education, vol. 92, pp. 123-131, 2003.

GEORGE M. NICKLES III is a post-doc research associate in the ITS Center at Texas A\&M University. He earned his $\mathrm{PhD}$ in Industrial and Systems Engineering at Georgia Tech in 2004 with an emphasis in Human-Integrated Systems and a minor and certificate in Cognitive Science. His research interests include cognitive engineering, educational technology, and evaluation of education. 